\title{
New Digital Cinema: How Platforms Are Changing the Audiovisual Industry
}

\author{
Antonella CAPALBI ${ }^{1}$ \\ Tommaso FABBRI ${ }^{2}$ \\ Vittorio IERVESE ${ }^{3}$ \\ University of Modena and Reggio Emilia \\ Modena, Italy \\ ${ }^{1}$ e-mail: antonella.capalbi@unimore.it \\ ${ }^{2}$ e-mail: tommaso.fabbri@unimore.it \\ ${ }^{3}$ e-mail: vittorio.iervese@unimore.it
}

\begin{abstract}
Digitalization has been changing the methods of production, distribution, and use of written and audiovisual products, according to a process of "platforming". Most audiovisual content is available via streaming platforms, through a lot of devices (PCs, tablets, smartphones, smart TVs, and videogame consoles), which have empowered the process of media convergence. Based on a theoretical framework related to the impact of the platforms on the ongoing process, we intend to analyse how platforms are changing the identity of the audiovisual industry and how they represent themselves online. In order to analyse the ongoing process, we intend to examine some platforms that could be considered as best practices in the audiovisual field: Netflix, MUBI, and Festival Scope. On the one hand, using these platforms as case studies will enable us to highlight some beneficial aspects of the ongoing process of digitalization and platforming: holding many gazes and points of view; catching market niches; building a peer-to-peer network. On the other hand, we intend to emphasize some risks connected to the intermediation of platforms in the audiovisual field in terms of economic, cultural, and social effects.
\end{abstract}

Keywords: platforms, audiovisual industry, cinema, digitalization

\section{Introduction}

Digitalization has been changing the methods of production, distribution, and use of written and audiovisual products, according to a process of "platforming" (Van Dijck-Poell-de Waal 2018). Most audiovisual content is available via streaming platforms, through a wide range of devices (PCs, tablets, smartphones, smart TVs, 
and videogame consoles). This has empowered the process of media convergence (Jenkins, 2006).

The following analysis aims to investigate the ongoing process related to audiovisual products and its impact on the identity of the audiovisual industry. In order to analyse the ongoing process of digitalization, we will start from a theoretical framework related to the impact of platforms on the audiovisual industry. Then, we will analyse in depth some platforms of audiovisual content that we considered as best practices. The aim of the analysis is to highlight opportunities and risks connected with the ongoing process of "platforming" and its result with regard to the audiovisual industry in terms of organizational identity.

\section{Platforms and "Streaming Revolution": A New Identity for the Audiovisual Industry}

During the $20^{\text {th }}$ century, the audiovisual industry was characterized by the "Hollywood model", which was a "fordist" pipe-based model (Hesmondhalgh, 2005; Manovich, 2001) in which a small circle of producers offered their products to many consumers, according to the classic value chain model. "Pipeline businesses create value by controlling a linear series of activities [...] Inputs at one end of the chain (say, materials from suppliers) undergo a series of steps that transform them into an output that's worth more: the finished product” (Parker et al., 2017: 4). From this point of view, the platform model has introduced a new mindset that thinks horizontally, connecting producers and consumers within a digital environment, breaking down space-time barriers, controlling data, and simplifying the supply chain (Iacovone, 2017; Guarascio-Sacchi, 2018).

Indeed, according to OECD (2019), "an online platform is a digital service that facilitates interactions between two or more distinct but interdependent sets of users (whether firms or individuals) who interact through the service via the Internet" (23). So, the audiovisual field has undergone a transition, from "monomedia industry" to "multimedia industry" (Preta, 2007), because the use of audiovisual products is now connected to different digital platforms, devices, and media. Therefore, the new audiovisual industry is based on some fundamental elements: content, cheapness, and control over data (Corvi, 2020).

Moreover, platforms provide an open infrastructure, which encourages user participation and satisfaction, spread by feedbacks thanks to social media (Brunetta et al., 2017). Thus, even the audiovisual field has undergone a transition to companies with a service provider role, following a user-based model that feeds different forms of participation and spreadability through intermediality and storytelling (Jenkins et al., 2013; Salmon, 2007). From this point of view, by making 
a comparison between media ecosystems (Pescatore-Innocenti, 2011) and some economic theories about cultural and creative industries (Montanari, 2018), we can consider an online platform also as a creative ecosystem: an environment, digital or otherwise, that becomes a place of co-production of content thanks to the users. This produces a different role of the users who, according to the service economy, have undergone a transition from passive consumers of products to active users of services (Brunetta et al., 2017).

Indeed, the new audience can enjoy lots of audiovisual content, so users are more discerning. This is typical of "prosumer culture" (Collins, 2010), characterized by users' ability in terms of "distinction" (Bourdieu, 1984), which produces personalized media (Tryon, 2013). According to Abercrombie and Longhurst (1998), the new audience is more and more "skilled" because consumers have access to lots of audiovisual content, wherefore they are more discerning. This active role is so different from the passive role of consumers more typical of the previous pipe model because online products and services are constantly examined and compared on the web or through mobile services. Information about consumers is disseminated on blogs, forums, and social networks. In this way, consumers themselves are part of the production process (Brunetta et al., 2017).

So, the on-demand culture, the online dimension, and the personalization of the offer have a strong synchronous, collective, and community dimension. Social platforms become the place where users can comment and where they unintentionally advertise audiovisual content provided by streaming platforms. This is a new marketing method based on engagement, which is typical of longtail markets (Anderson, 2006). Thus, the audience, selective and widespread, brings authenticity and transparency into its online word-of-mouth activity. So, it alternately becomes a consumer and a producer of value, according to a double thread that binds vision, use, intermediation, and storytelling (Jenkins et al., 2013; Salmon, 2007). This produces a different kind of audience that is not national but global and watches films or film series in their original language. The new audience is inclined to consume more episodes of a series at once (binge watching) and to comment in a continuous stream on social media (Corvi, 2020).

Therefore, the consumption of content is not contained within the boundaries of the streaming platform, but it finds space, like a river flood, in the other media streams that make up the web, in a continuous intermedial dialectic. For this reason, Severo proposes an analysis of the impact of platforms on user participation in a multimodal and multi-space perspective (Severo-Thuillas, 2020) in order to explore the dialectic of what Jenkins (2013) defines as "transmedia storytelling".

Transmedia storytelling is extremely empowered by the structure of the platforms, which constitute the open infrastructure within which content users can meet, discuss, enrich the narration from a transmedia perspective and produce new ones. Therefore, consumers of content start to have an active role 
and become themselves producers of content. This has strong effects on the "spontaneous" marketing of the audiovisual product (Anderson, 2006). At the same time, this use of content has deep effects also on the very identity of the consumer, which is extremely influenced by the experience of online use in the context of the so-called performative society (Abercrombie-Longhurst, 1998). Images taken from audiovisual series or cinema flood the social channels. They become profile photos in the communities or avatars of the characters performed in the identity game played in the virtual reality. Thus, the virtual identity becomes an appendix, and not an antagonist, of the one that is built in real life (Floridi, 2014; Dean, 2010).

This is why the main concern of platforms is about user experience. Streaming platforms are characterized by a refined customer profiling just to please users' high expectations (Corvi, 2020). Therefore, the high quality of user experience is strictly connected to the platform's ability to profile their tastes and interests. This makes the data dimension crucial.

Indeed, on the one hand, users provide a large amount of data on their profiles and consumption choices, which are used by the platform to track their user experience and sometimes for marketing purposes too (Corvi, 2020). On the other hand, platforms use lots of metadata just to organize the audiovisual content, which is classified according to several criteria specific for each platform, thus establishing their own taxonomy, useful to their business model (Avezzù, 2017).

Therefore, organizing audiovisual content is a technical process driven by human perception: "There is much more than meets the eye, in the setup and operation of these systems: theory, subjectivity, unquestioned (scientistic) assumptions, judgements, values, habits. People who decide, define, describe, choose, interpret, think and believe" (Avezzù, 2017: 65). Platforms act as filters and as non-neutral intermediaries within user experience because data are never meaningless (Compagno-Treleani, 2019): "Data are never neutral, in the sense of being unaffected by the observer's procedures" (idem: 2).

The data dimension is increasingly crucial, especially if we consider that some online platforms can involve different entities. Because of the pandemic, for example, different cinemas or film festivals join an online platform not only to distribute their audiovisual content but also to build up strategies and creative solutions to face the pandemic situation. If we take a glance at the Italian context, for example, we can see that in 2020 the experience of Italian film festivals was mediated by platforms due to the COVID-19 pandemic. According to a report published by AFIC (Italian Film Festival Association) that investigated the experience of 142 film festivals during the pandemic of 2020, 29\% of these film festivals were held entirely online, $28 \%$ online and offline, and only $31 \%$ entirely offline. So, platforms had a major role in this digital transition as solutions to face the pandemic emergency. From this point of view, some online platforms 
connected to the audiovisual industry may be considered as digital ecosystems, being "combinations of interoperating applications, operating systems, platforms, business models and/or hardware, and not all components of the ecosystem must be owned by the same entity. In fact, a digital ecosystem may involve thousands of different businesses" (OECD, 2019: 24).

\section{CLAP - Cultural Lab Platforming}

User experience, access to a large amount of content, control over data, circularity between producers and consumers, elimination of space-time barriers, building a global audience - all seem to be the basic ingredients of the magic recipe that allowed the platform models to climb to the top of the international market and specifically the audiovisual supply chain. Obviously, the ongoing change, accelerated exponentially by the COVID-19 pandemic, implies an impact of the platforms on the audiovisual ecosystem from many points of view. The impact of platforms on the audiovisual industry is becoming more and more relevant, so it could be useful to highlight the beneficial effect of platforms and, at the same time, to stress the new issues connected to the ongoing process.

In this sense, the following analysis is part of the research activities developed within CLAP (Cultural Lab Platforming), which is an innovation programme of the University of Modena and Reggio Emilia. This programme is aimed at developing research on creative and cultural industries. According to a strong connection between technology and humanism, between traditional and innovative crafts, the specific objectives of the project are the production of original research that can generate new educational and training content, new job opportunities for young people, and prototypes of innovations for creative and cultural industries.

According to this framework, the research developed within CLAP revolves around the concept of cultural platforming, which consists in the systematic application of platform logics to cultural and creative industries. The ultimate goal of the programme is to create new models for the enhancement and use of cultural content and, at the same time, to experiment with them through digital citizenship initiatives. Within this framework, the audiovisual field constitutes a specific area of investigation. Like other cultural and creative sectors, the audiovisual industry is in fact going through a profound process of change, accelerated exponentially due to the COVID-19 pandemic. Therefore, CLAP proposes a reflection on which opportunities can be generated by the platforming of the audiovisual supply chain and which are the critical issues resulting from the process. For this reason, we will analyse in depth (Eisenhardt, 1989) some good practices of platforms related to the audiovisual industry, with the aim to highlight opportunities and challenges of the ongoing process. Indeed, these good practices clearly exemplify 
some innovative aspects of the platform model. Moreover, we will highlight how the process of "platforming" is changing some habits of the audiovisual industry and, in a way, its identity too.

\section{Many Gazes and Points of View: Netflix vs Hollywood}

The impact of the platform model had the effect of a tornado on the previously pipe-based value chain within the audiovisual industry. Streaming platforms have been able to upset the whole audiovisual ecosystem in terms of production, distribution, use of content and, definitely, organizational identity. In this sense, the case of Netflix is emblematic because the platform upset Hollywood studios first due to the impact on all areas of the value chain (conception, financing, production, and distribution), in a scenario in which ticket sales in US theatres were already in crisis in the last decade (Corvi, 2020). Therefore, platforms have challenged Hollywood and its identity even before the pandemic. This was evident starting from 2019 when the Academy rewarded a film entirely and exclusively produced by Netflix (Story of a Marriage by Noah Baumbach). In the same year, The Irishman by Martin Scorsese was produced by Netflix, which was the only one with the economic resources to do so. This the reason why we can consider Netflix as a best practice.

Of course, this war of content, as it has been defined (Corvi, 2020), whose reward is essentially the time, rather than the money, of the users, has effects not only from an economic point of view but also on the identity of the industry and on its audiovisual content. In fact, the challenge between the previous pipe line model and the new platform model becomes a war of gazes and points of view too. Once again, it is not by chance that in 2020 Netflix USA produces a series provocatively entitled "Hollywood". The series, directed by Ryan Murphy, is based on the narrative mechanism of "what if". It wonders how the audiovisual productions of the 1950s would have been if in the big Hollywood production houses, and therefore in the audiovisual industry, there had been access for those who at that time were considered invisible and had no voice. So, Netflix implicitly wonders how could have been the society in the 50s if the audiovisual industry had had a different identity, more inclusive and equal. Moving from this question, the series unfolds along the effects of "what if". We can see leading roles assigned to African American women or the possible coming-out of actors no longer forced to hide their sexual orientation - the real case of Rock Hudson, a well-known actor, is programmatically resumed because in real life he was forced for a long time to conceal his homosexuality from the public.

The reason behind Netflix's interest in the inclusion of multiple points of view naturally does not ignore economic needs. On the contrary, this trend is 
strictly connected to the identity of the platform, which has a highly user-based structure and whose business model is based on the long-term satisfaction of its users (Iacovone, 2017). If the global and widespread audience is at the centre, the plurality of points of view to be represented and satisfied is also central. According to Jenkins (2006), despite the rhetoric about the "democratization of television", this shift is driven by economic interests and not by the social mission of empowering the public. Media companies view convergence favourably for various reasons: convergence-based strategies exploit the benefits of media conglomeration because it empowers consumer loyalty and engagement. This is the reason why Netflix represents itself as a house of inclusion on its platform and on its social media too. If we take a glance at Netflix Italia's Twitter, for example, we can see that on 22 June 2020 they posted a tweet specifically related to their intention to increase the number of audiovisual content with LGBTQ+ stories. ${ }^{1}$

Indeed, the new and more inclusive value paradigm, towards which the platform and its potential audience tend, seems to be increasingly dominant, with concrete cultural effects on the process of representation, in which cause and effect chase each other. The effect of this broadening of point of view, for example, seems connected to the choice of the Academy, controversial and at times disputed, to update the inclusiveness parameters underlying the selection for the Oscars. It is evident that also in this sense an approach aimed at broadening the spectrum of the point of view reflects the ongoing cultural change, also fed by the impact of platforms on the audiovisual representation circuit and on the related experience of the audience.

Hollywood seems to change its identity, or the representation of its identity, in order to compete with the new model built by big platforms such as Netflix that seems to encourage more and more the inclusion of multiple points of view and gazes. This trend, even if driven by economic interests, seems to be able to feed a cultural change, whose fuel is a process of socialized imagination. This process is driven by the images, the stories - in a word: the resources - drawn from the immense reservoir of mass media. Media and audiovisual products cross and permeate the social world with their models of style, with their stories, with the icons and sounds that provide the imaginative fuel essential for late modern daily life (Scaglioni, 2006).

\section{Catching Market Niches: MUBI}

The broadening of the spectrum of the point of view is not the only consequence resulting from the new notion of audience built by digital and, specifically, by

1 Spesso ci dicono che i nostri titoli sono pieni di personaggi LGBTQ+. Sapete cosa? Ne vogliamo mettere ancora di più. Direttamente nei titoli. 'They often tell us that our titles are full of LGBTQ+ characters. You know what? We want to add even more. Directly in the titles.' The English translation of the tweet is made by the authors of this paper. 
the new platform model. Indeed, if the audience takes on a global dimension, some trends that were market niches from a local point of view can spread on a global scale and find their sustainability. According to a typical feature of long tail markets, consumer niches, no longer relegated to a territorial level, can spread on an international level thanks to digital media. They can intercept interests and tastes that converge within a widespread audience.

Therefore, long tail markets allow the elimination of the so-called "tyranny of geography" (Iordanova-Cunningham, 2012) since they allow the customers to find what they are looking for within "online spaces" defined as "aggregators" (Anderson, 2006). Aggregators have lower market access barriers and, at the same time, allow an increasing number of products to overcome that obstacle and get to where they can find their audience (Anderson, 2006). Thus, a product that is difficult to find on a local scale can become easily accessible on a global scale, within a platform able to break down space-time barriers. In the "Internet Galaxy" mentioned by Castells (1996), populated by cybernauts who are discerning in their choices of use, there is a space of sustainability for market niches.

We can particularly highlight this aspect within the audiovisual industry by examining the case of MUBI. The platform represents the concrete example of how media convergence (cinema, streaming, smartphone) also becomes a cultural convergence: the high-level and the low-level mix, in a context of use in which niche films become easily accessible through different devices. This aspect has been exponentially accelerated by the COVID-19 pandemic. Specifically, MUBI had more visibility in 2020, the year in which everything became (smart) TV, according to The New York Times. ${ }^{2}$ In fact, looking at the Italian context, this aspect seems to be confirmed by the proliferation of domestic screens detected by the $54^{\text {th }}$ CENSIS report. According to CENSIS, in Italy, the figure of 112 million devices has been reached and, specifically in 2020, the purchase of smart TVs involved 17 million Italians. This confirms the intense acceleration of the media collision process that has already been underway since long ago. We can say that MUBI has taken advantage of this process to build its identity as a platform and to build its successful business model. This is the reason why we can consider MUBI as a best practice.

Indeed, the platform was founded by Efe Çakarel in 2007, a long time before the COVID-19 pandemic. The core of the platform is the streaming service provided for users, who can enjoy a careful and accurate selection of non-mainstream films. In this way, MUBI is able to exploit the potential of a market niche that finds its sustainability on a global scale. The platform manages to aggregate art cinema enthusiasts from around the globe.

2 Poniewozik J. (2020). This Was the Year When Everything Became TV. The New York Times 9 December. https://www.nytimes.com/2020/12/09/arts/television/everything-became-tv.html. 
The mission of the platform consists in the collision of the media mentioned by Jenkins (2006), as it presents vision proposals selected by the administrators of the platform. They build a true digital video library, accessible at cheap prices. Knocking down the space-time barriers in order to exploit market niches is the ultimate goal of the platform. This is clear if we look at the claim that appears in the information section of the website, which underlines that one can avail themselves of the films made available by MUBI “Always, everywhere”. So, MUBI wants to represent itself as a place in which you can always find what you need in terms of niche audiovisual content, beyond any space or time limits.

Furthermore, as a user-based platform, the user is at the centre and is the active engine of the platform. Indeed, MUBI is presented as a space in which one can enjoy the films but can also meet a community of enthusiasts with whom to confront or discuss about authors, style, and movies. In the spirit of platform design, the reference community is well identified. Taking community as a starting-point, the platform is shaped according to the needs of the user, who has the possibility to create his/her own movie playlist, visible to all users. In this way, the platform is able to offer an integrated service based on user-generated content. A specific section is also dedicated to users' feeds, who debate on what they have viewed and generate additional content. Therefore, the platform manages to enhance the active role of the user, from a "prosuming perspective", in order to build a loyal and global audience.

\section{Building a Peer-To-Peer Network: Festival Scope}

The revenge of market niches does not only affect streaming platforms but can also find space within a context in which fewer mainstream productions have always been at ease: the festival ecosystem. In fact, most films are not seen outside the circuit of festivals or private screenings (Boccardelli, 2008). Therefore, festival contexts have always represented the favourite territory for the production and distribution of less mainstream audiovisual products. Sometimes festivals support not only the distribution but also the production of the film, through specific industry and pitching activities. Somehow they assume the role of sponsor for the production. From this point of view, the ability of platforms to extend market niches from a global perspective is particularly significant for the festival circuit.

Moreover, the connection between festivals and platforms is strictly related to another element typical of the platform model: circularity. Indeed, in the ongoing process of digital transition and "platforming" of the audiovisual industry, the greatest transformation is perhaps the passage from individual and personalized media consumption to what is experienced as a collective and networked practice (Jenkins, 2006). It is a passage of consumption, which has as a side effect that users are more and more involved in the perspective of collective participation 
and collective intelligence. Rather than talking about personal media, we should talk about community media: media that involve our lives as members of various communities, both locally with physical experience and online (Jenkins, 2006). Therefore, within a digital space, it is possible not only to reach a global and widespread audience but also possible to build a space in which to network among peers, as members of a community.

These two aspects can be particularly observed by examining the case of Festival Scope. It is a comprehensive platform for festivals that since 2011 allows its visitors to follow the programmes of different festivals, even if physically not present. Thus, the platform allows a breakdown of space-time barriers and, at the same time, intercepts market niches. This is the reason why we can consider Festival Scope as a best practice that expresses all its potential due to the pandemic emergency, according to a circular network logic that links producers, festival organizers, and users.

The platform offers various services related to the reference target. In this sense, it proposes a double interface, designed for two types of users: "basic" and "pro". The interface designed for the "basic" user allows to follow the schedule of the different festivals from home, making the films available on the user's account for a period of five days. The platform also provides technical support for the user: it offers information to facilitate use and specifies the necessary requirements for the different devices. The interface designed for the "pros" is the Festival Scope Expanded, which allows a multifaceted and diversified use of the platform. This use is not limited to providing a streaming service of the festival programme, but it outlines the possible needs of the "skilled" user (Abercrombie-Longhurst, 1998). It provides a more specific and diversified user experience thanks to a heterogeneous offer from an extremely user-based perspective.

Moreover, besides the double interface, there is a section of services designed for festival managers and organizers. The platform allows you to create your own festival online, offering support for the whole process thanks to the collaboration with Shift72, a service platform that follows digitalization paths. It takes care of moving on-line not only festivals but also cinema, broadcaster, and brand. Thanks to the support of Shift72, Festival Scope allows you to directly create an online festival using their own platform. Thus, it offers high-quality streaming infrastructures, rapid platform development, integrated payment system, and other similar services. In this sense, as a digital ecosystem (OECD, 2019), the platform is absolutely user-based, but it also becomes a context of co-production and co-design. This is the reason why the platform is presented as a place where one can use lots of Film Festivals, as well as enable users to create their own Film Festival, taking advantage of the digital infrastructure and the network available through the platform. Indeed, the platform is able to make use of the collaboration between peers through the digital world in a global perspective, putting online festivals within a network based on the platform, which also offers to look after its digitalization process. 


\section{Some Critical Issues}

As can be seen from the analysis of the good practices previously discussed, the impact of platforms on the audiovisual supply chain has been evident, with beneficial effects on the audiovisual industry. However, it must be noted that each of the aspects of innovation can also hide some critical issues.

First of all, if it is true that user-centricity is a relevant element of platforming, in terms of activity and from a "prosuming perspective", it is also true that there is no lack of critical readings regarding how much this role is really active. Indeed, we can observe that user experience on large digital platforms is inevitably guided by algorithms. Even if Netflix and other mainstreaming platforms often propose a "democratization rhetoric", just in order to engage their audience (Jenkins, 2006), the role of the platform is relevant as intermediary. In fact, it is clear how much the process of organizing information, and therefore taste, is driven by platforms, which represent the open infrastructure in which interactions take place and on which our interactions are increasingly dependent. This happens in different contexts of our social life such as school, health, information, and entertainment (Van Dijck-Poell-de Waal, 2018). The role of platforms is predominant in contemporary life concerning various aspects: data management, transparency, security, and information. So, for what concerns the audiovisual industry, it is useful to highlight how platforms let the use of audiovisual content be more "democratized", while platforms also have an important role as intermediaries by managing data and content.

Therefore, on the one hand, the platform model supports the active role of users, from a prosumer perspective. This is the reason why many platforms insist on this aspect when they represent themselves on their social media. But, on the other hand, user experience is guided and mediated by the platform that organizes metadata with a very "human" gaze and with several criteria perhaps influenced by several biases. So, although the inclusion of users in the consumption choices promotes their active use, there is the risk of use still being guided by algorithms. This could produce participation bubbles, in which one communicates with those who have a point of view or taste already very similar to their own, according to a polarized "collaborative individualism" (Bandinelli-Gandini, 2019; Klein, 2020) rather than a real sense of community (Tryon, 2013).

If we consider this framework, there is also the risk of an American editorial perspective, especially because mainstreaming platforms are often strictly connected to main American companies (Van Dijck-Poell-de Waal, 2018).

Furthermore, platforms often have some geographical limitations because of which users see different content in different regions. So, even if platforms are able to knock down space-time barriers, there is also a risk of enforcing geographical boundaries and creating "geographical bubbles". 
Some potential risks are finally connected to the heterogeneity of the catalogue. Even if streaming platforms often promote the active role of users in terms of content selection, the catalogue is often shown through some filters and placed in categories that are based on different criteria preselected by the platform. These criteria are often connected to previous user experiences, to the similarity between the different content and, obviously, to the business model of the platform. According to Avezzù (2017), from this point of view, "Recommender systems do not really promote discovery: on the contrary, the criteria regulating the patterns of similarity tend to reduce the complexity of a catalogue" (Avezzù, 2017: 64).

So, we can say that platforms could have a beneficial impact on user experience in terms of active role but, at the same time, we need to consider the non-neutral role of platforms in organizing data and metadata, which also have a significant impact on user experience. This role could become increasingly crucial for platforms that, as digital ecosystems, involve different entities.

\section{Conclusive Remarks}

In conclusion, based on the theoretical framework and the in-depth analysis of good practices, we can say that the impact of platforms on the audiovisual industry, and its identity, is becoming more and more relevant.

We can see that the impact of the platform model on the audiovisual supply chain can be beneficial by several points of view. In fact, platforms are able to knock down space-time barriers, broaden the audience on a global scale, support the inclusion of multiple points of views and gazes within the audiovisual representation, allow collaboration between peers, and support the emergence of market niches. All these aspects are often stressed by platforms - when they represent themselves online - as elements of innovation.

However, at the same time, we need to think of the potential critical issues arising from the non-neutral inclusion of a third entity, the platform, in the experience of production, distribution, and the use of audiovisual content. As is already happening in other fields, such as communication (Boccia Artieri-Marinelli, 2018), this inclusion can have strong effects in terms of economic, social, and cultural trends.

\section{References}

Abercrombie, N.-Longhurst, B. (1998). Audiences. A Sociological Theory of Performance and Imagination. London: Sage.

Anderson, C. (2006). The Long Tail, Why the Future of Business Is Selling Less of More. London: Random House Business Books. 
AFIC. (2021). Piattaforma Festival. Roma: AFIC.

Avezzù, G. (2017). The Data Don’t Speak for Themselves: The Humanity of VOD Recommender Systems. Cinéma \& Cie 17(29): 51-66.

Bandinelli, C.-Gandini, A. (2019). Hubs vs Networks in the Creative Economy: Towards a 'Collaborative Individualism'. In: Gill, R.-Pratt, A.-Virani, T. (eds.), Creative Hubs in Question. Dynamics of Virtual Work. Cham: Palgrave Macmillan, 89-110.

Boccardelli, P. (2008). Strategie e modelli di business nell'industria del video entertainment. Milan: Il Mulino.

Boccardelli, P.-Iacovone, D. (eds.). (2017). L'impresa di diventare digitali. Milan: Il Mulino.

Boccia Artieri, G.-Marinelli, A. (2018). Piattaforme, algoritmi, formati. Come sta evolvendo l'informazione online. Problemi dell'informazione XLIII(3): 349-368.

Bourdieu, P. (1984). Distinction: A Social Critique of the Judgment of Taste. Mass., Harvard: University Press.

Brunetta, F.-Peruffo, E.-Pinelli, M. (2017). Il contesto digitale e il nuovo modello di consumo. In: Boccardelli, P.-Iacovone, D. (eds.), L'impresa di diventare digitale. Come la rivoluzione tecnologica sta influenzando la gestione di impresa. Milan: Il Mulino, 21-56.

Castells, M. (1996). Network of Outrage and Hope. Social Movement in the Internet Age. Chichester: John Wiley and Sons.

CENSIS. (2020). $54^{\circ}$ Rapporto sulla situazione sociale del paese. Roma: CENSIS.

Collins, S. (2010). Digital Fair Presumption and the Fair Use Defence. Journal of Consumer Culture 101: 37-55.

Compagno, D.-Treleani, M. (2019). Introduction to Meaningful data/Données signifiantes. Semiotica 230: 1-17.

Corvi, E. (2020). Streaming Revolution. Palermo: Flaccovio Dario.

Dean, J. (2010). Blog Theory: Feedback and Capture in the Circuits of Drive. Cambridge: Polity Press.

Eisenhardt, K. M. (1989). Building Theories from Case Study Research. The Academy of Management Review 14(4): 532-550.

Floridi, L. (2014). The Onlife Manifesto. Being Human in a Hyperconnected Era. New York: SpringerOpen.

Guarascio, D.-Sacchi, S. (2018). Digital Platform in Italy. An Analysis of Economic and Employment Trends. Policy Brief 8. Roma: INAP.

Hesmondhalgh, D. (ed.). (2005). Media Production. New York: Open University Press.

Iacovone, D. (2017). Le nuove opportunità per il go-to market e il ruolo della customer experience. In: Boccardelli, P.-Iacovone, D. (eds.), L'impresa di 
diventare digitale. Come la rivoluzione tecnologica sta influenzando la gestione di impresa. Milan: Il Mulino, 135-162.

Iordanova, D.-Cunningham, S. (eds.). (2012). Digital Disruption: Cinema Moves On-Line. St Andrews: St Andrews Film Studies.

Jenkins, H. (2006). Convergence Culture. New York: New York University Press. Jenkins, H.-Ford, S.-Green, J. (eds.). (2013). Spreadable Media. New York: New York University Press.

Klein, E. (2020). Why We're Polarized. New York: Avid Reader Pr.

Manovich, L. (2001). The Language of the New Media. Massachusetts: MIT press. Montanari, F. (2018). Ecosistema creativo: organizzazione della creatività in una prospettiva di network. Milan: FrancoAngeli.

Nasta, L.-Pirolo, L. (2017). La trasformazione dell'offering abilitata dalla rivoluzione digitale. In: Boccardelli, P.-Iacovone D. (eds.), L'impresa di diventare digitale. Come la rivoluzione tecnologica sta influenzando la gestione di impresa. Milan: Il Mulino, 113-134.

OECD. (2019). An Introduction to Online Platforms and Their Role in the Digital Transformation. Paris: OECD Publishing.

Parker, G. G.-Van Alstyne, M. W.-Choudary, S. P. (eds.). (2017). Platform Revolution. How Networked Markets Are Transforming the Economy - And How to Make Them Work for You. New York: W. W. Norton \& Company.

Pescatore, G.-Innocenti, V. (2011). Architettura dell'informazione nella serialità visiva. IMAGO 3: 135-144.

Preta, A. (2007). Economia dei contenuti. L'industria dei media e la rivoluzione digitale. Milan: V\&P.

Salmon, C. (2007). Storytelling. La machine à fabriquer des histoires et à formater les esprits. Paris: La Découverte.

Scaglioni, M. (2006). Tv di culto: la serialità televisiva americana e il suo fandom. Milan: V\&P.

Severo, M.-Thuillas, O. (2020). Plates-formes collaboratives: la nouvelle ère de la participation culturelle? NectArt 11: 120-130.

Toffler, A. (1980). The Third Wave. New York: Bantam Books.

Tryon, C. (2013). On-Demand Culture. Digital Delivery and the Future of Movies. New Brunswick, NJ: Rutgers University Press.

Van Dijck, J.-Poell, T.-de Waal, M. (eds.). (2018). The Platform Society. Public Values in a Connective World. Oxford: Oxford University Press.

\section{Cite as:}

Capalbi, A.-Fabbri, T.-Iervese, V. (2021). New Digital Cinema: How Platforms Are Changing the Audiovisual Industry. Acta Universitatis Sapientiae, Communicatio 8: 22-35. DOI: 10.2478/auscom-2021-0002. 